\title{
Decision Support System Design for Wedding Organizer Tradeshow Selection using AHP and TOPSIS
}

\author{
Rayinda Pramuditya Soesanto ${ }^{1 *}$, Afrin Fauzya Rizana ${ }^{2}$ \\ 1,2,3 Telkom University \\ Jl. Telekomunikasi No. 1, Bandung, 40257, INDONESIA \\ *raysoesanto@telkomuniversity.ac.id
}

\section{ARTICLE INFO}

Article history:

Received 10 September 2020

Accepted 25 January 2021

Published 31 January 2021

Keywords:

AHP, Agile SCRUM ,

Decision Support System,

TOPSIS, Trade Show.

\begin{abstract}
IN ENGLISH
Wedding organizers, as one of the creative industries, often participate in a trade show as one of the marketing mediums. Many wedding-related trades show events are held every year. But the cost to participate in one trade show event is quite expensive and increases from time to time. Thus, before deciding to participate in a trade show, it is important to evaluate whether the trade show events are recommended to join or not. The purpose of this study is to design a decision support system that will help the wedding organizer to decide their participation in a trade show. The decision model was constructed using AHP and TOPSIS methods. There are seven factors considered in the model, i.e., tradeshow location, reputation and professionalism of the organizer, cost estimation, trade show prestige, tenant reputation, time of the event, the attractiveness of the event. By using the AHP method, the priority weight of each factor was calculated. Moreover, the weight obtained will be used in developing a decision model combined with the TOPSIS method. The decision support system was developed afterward by using the SCRUM method. The feature of the system is discussed in the paper.
\end{abstract}

\section{Introduction}

One of the promotion media that is considered effective is a trade show. It is because about $85 \%$ of trade show visitors have high buying intention [1]. There is no doubt that many creative often participate in the trade show. Trade shows are defined as market events that are held in a specific duration of time where a large number of participants present their product or service [2]. The term "trade show" often interchangeably with other terms such as exhibitions, fairs, and expositions [3]. The trade show can help participants in identifying buying influence, boosting image, providing product demonstration, etc. [4]. Other than that, participating in a trade show can help the participant to create awareness of new products or services, reinforce the existing relationship with the customer, provide product or service demonstration, allow sales of product or service on-site, etc. [5]. Many expertise considers trade show as a chance for the small industry to act as an established industry or known as a level playing field [1]. In a trade show, a new company can compete with a well-established company and have the same chance to promote its product in such an event. One of an industry that often participates in a trade show is the creative industry.

Wedding organizers, as one of the creative industry, often participate in a trade show as one of the marketing mediums. Many wedding-related trades show events are held in every year. But, the price to participate in one trade show event is quite expensive and increases from time to time. Other than that, lots of time and effort should be put into participating in a trade show. Thus, before deciding to participate in a trade show, it is important to evaluate whether the trade show events are recommended to join or not. Without careful assessment of a particular trade show, trade show participants might suffer a loss because the results obtained from a trade show are not worth all the 
effort they put in it. Trade shows usually needs a large marketing budget but regards as an effective promotional tools for marketing product and service [6]

There are several factors that should be considered before joining in a tradeshow, i.e. location where the event held, participants' booth location, reputation and professionalism of the organizer, trade show cost estimation, the prestige of the event, and reputation of other participants [1]. The factors considered in participating in a trade show can be assessed and calculated by using multi-criteria decision-making (MCDM) method such as AHP and TOPSIS. Decision support system can help making a decision based on predetermined criteria [7]. Thus, the purpose of this study is to design the decision support system to provide the recommendation of the wedding organization participation in a trade show. The system can help the wedding organizer to assess the performance of the trade show even before the event was held.

\section{Literature Review}

Trade show or expo is an event that consist of a group of seller that gathered in one place to showcase and sells the product [8]. The benefit of trade show is to give an opportunity to the seller to introduce their products to market and reveal their potential customer and gain free publicity. Trade show can give the exhibitors the opportunity to meet potential buyer with high chance of buying [9]. Previous similar study is done by Guan et al. [10], Lau and Hui [11], and Ardani [12], but the main concern of the study is in the selection of wedding venue. There are few study that focused on the decision regarding the tradeshow selection. The trade show selection criteria that is similar to this study is the study from Rizana et al. [1] that emphasized the importance of criteria for tradeshow which are Tradeshow location, Booth position, Reputation of Organizer, Cost Estimation, Prestige of the Event, and other participant reputation. Because of the similar characteristic, the model form Rizana et al. [1] will be used as the basis of this study.

The AHP Method comprises different decision analytical methods, which are applicable to addressing problems with multiple criteria. According to Saaty [13], Analytical Hierarchy Process (AHP) is a decision method that can solve the decision problem with multicriteria decision. In solving a problem with AHP, there are 5 principal, which is decomposition, comparative judgement, synthesis of priority and logical consistency. The decomposition means that the problem must be derived into hierarchy. Comparative judgement means that the value of the element in same hierarchy must be filled with some degree. The priorities then is synthesize and then checked if the logic is consistence. The step by step procedure to use AHP as follows [14]:

1. The decision criteria should be stated in the form of a hierarchy of objectives. The hierarchy has various levels starting with the highest goal and descending through intermediate criteria and sub criteria to finally the lowest level (i.e. the alternatives).

2. Evaluate each criterion, sub-criterion, and alternative on a numerical continuum using the factors that are most important for each criterion. For the purpose of this study, AHP used simple pairwise comparisons to determine ratings and weights so that the analyst can focus on only two issues at a time.

3. After the judgment matrix is developed a priority vector is calculated to prioritize the various elements within the matrix. Priority vectors are calculated by solving an eigenvalue problem and then they are compared by summing them.

4. Assess the consistency of the judgement relative to the consistency ratio IR. To determine an inconsistency measurement, it is first necessary to introduce the consistency index (CI) of the matrix of judgements.

Dirpan [15] state that TOPSIS method can be used to obtain the final ranking of alternatives. The basic principle of this method is to choose the solution that is most advantageous, but to also choose the solution that is least disadvantageous. In TOPSIS, personal judgments are represented with clean, precise values. However, in many realworld situations, the human preference model is uncertain and decision makers may be reluctant or unable to make clear distinctions among alternatives. The ideal answer will have a rank of one and the worst answer will be judged to be close to zero. The TOPSIS model involves using the following steps: Development of decision matrix; and Algorithm used to find normalized decision matrix. The objective of normalization is to transform how something is measured into a single dimensionless number.

Decision Support System (DSS) are interactive computer-based systems that use the data, models, documents, knowledge and communication technologies required to support people who are needed to solve complex problems [16]. DSS has been one of the most attractive research topics since its inception in the early 1970s and faced a number of challenges due to rapid development and innovation in the field of information technology. In the wedding industry there are a lot of study of DSS, but the decision support for trade show for wedding organizer is given little attention. However, IT also offers opportunities for show organizers, exhibitors and visitors. [17] According to Layton [18], SCRUM is simple framework for clearly identifying roles and organizing More effective in prioritizing tasks, and more efficient in completing work set forth. SCRUM is an iterative, incremental approach. The process of scrum is quick and efficient; inspection and adaptation being the constant element: 
- A daily project list called a product backlog.

- Top priorities are selected for a fixed, regular, time box called a sprint in which the scrum team strives towards a predetermined goal.

Scrum Teams consist of Product Owners, Scrum Team Members, events, artifacts, and rules. Each component works well in Scrum to contribute to its success and usage [19]. Scrum has been used for software development, hardware, embedded software, networks of interacting functions, autonomous vehicles, school, government, marketing, organization management, and practically everything else we use in our daily lives. Scrum performed particularly well for iterative and incremental information distribution.

\section{Research Method}

The purpose of this study is to design a decision support system that will help the wedding organizer to decide their participation in a trade show. The decision model was constructed using the AHP and TOPSIS method and the application development phase is using the agile SCRUM method. By using SCRUM, the development process is using the iterative and incremental phase, not like the conventional one that focused on step by step. The benefit of using SCRUM is it is easier to trace when there is an error in the development phase [20].. In the SCRUM method, every phase is not mandatory to be done sequentially but the development time is faster because the planning time is reduced. Each iteration is done by sprint planning. Stakeholders takes an important role in this method because there is a lot of involvement of stakeholders in each phase of this method. Figure 1 shows the SCRUM phase.

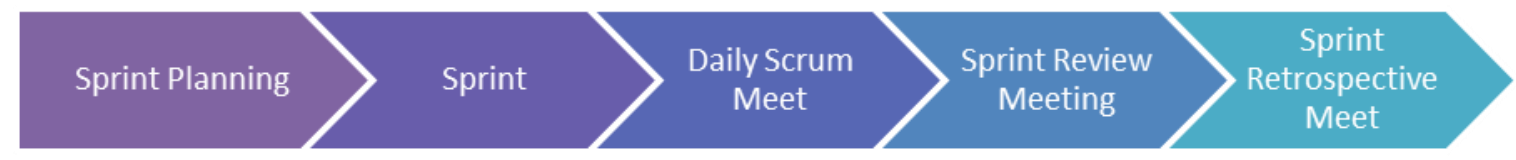

Fig. 1 - SCRUM Phase

The first phase is to determine the product backlog, the product backlog is the list of the desired feature in the system that achieves the objective and meets the stakeholder expectation. The product backlog was then picked into the sprint planning. In the first sprint, the decision model is developed using AHP to gain the weight of each indicator. The criteria that are used in this study are from Fauzya et al. [1]. AHP is considered as effective method for solving complex problem in decision making [21] and help the expert as to make best decision. To refine the criteria, the questionnaire is used and spread into the owner of the Wedding Organizer service in Bandung. After the criteria are identified and refined the next step is to create the decision support calculation using the TOPSIS method. In the development of each sprint, the interface and other functions are developed. Testing is done to give internal validation and to trace if there is any bug in the dashboard and other functions, black box testing is used in this research. After the functionality is tested the next step is to test the usability. The usability testing is done to a member of the wedding organizer association in Bandung.

\section{Result and Discussion}

\subsection{Requirement Identification}

Stakeholders is an individual, group of people, organization, or other entity that has a direct or indirect interest in a system [22], stakeholders in scrum is scrum roles. To identify the stakeholders, stakeholder analysis by Daellenbach [23]. Table 1 shows the stakeholder identification result.

Table 1 - Stakeholders Identification

\begin{tabular}{cc}
\hline Role & Stakeholders \\
\hline Problem Owner & Wedding Organizer Owner \\
Problem User & Wedding Organizer \\
Problem Customer & Client \\
\hline
\end{tabular}

After the stakeholders is identified, the next step is to define the product backlog. Product backlog is a list that consist of everything that needed to be in the product, and it is a single source requirements for any changes in the product [19]. The feature for the decision support system is obtained from the interview with the stakeholders. The interview is conducted with a representative of each role. There are 4 Wedding Organizer Owner, 2 Wedding 
Organizer staff and 3 client. Table 2 shows the main feature in that will be included in the development of the decision support system. Every feature will be list in the sprint backlog.

Table 2 - Product Backlog

\begin{tabular}{cr}
\hline Feature & Function \\
\hline Login & Is used to authenticate the user accessing the system \\
Tradeshow Data & Is used as initial data for tradeshow event \\
Tradeshow & Is used as the basis for calculation the alternative solution \\
Indicator & \\
Dashboard & Is used to display the calculation result in chart \\
TOPSIS & Is used to calculate the value form indicator and tradeshow alternatives. \\
Calculation & \\
\hline
\end{tabular}

After the product backlog is defined, the next step is to create the sprint planning. Sprint planning consisted of the work that needs to be performed. The work is selected from the product backlog and pulled into the sprint backlog. Table 3 shows the sprint planning for this study.

Table 3 - Sprint Planning

\begin{tabular}{cc}
\hline Feature & Function \\
\hline Sprint 1 & Login, Dashboard \\
Sprint 2 & Tradeshow Data, Indicator Data \\
Sprint 3 & TOPSIS Calculation \\
\hline
\end{tabular}

The product backlog that is included in the first sprint is the login function and dashboard because this is the basic function for the system and the basis for other functions. The second sprint consists of tradeshow data and indicators. The third sprint consists of TOPSIS calculation because all the previous function is used for the input of this function. Every sprint is set to 20 days deadline and the next day the sprint review meeting is conducted. If there is a product backlog that is not completed in the current sprint then it will be discussed in the meeting and will be included in the next sprint.

\subsection{System Design}

In this phase, the system needs are identified and the user right is assigned. User access right in the system is obtained from the stakeholders through the analysis in the previous chapter. The stakeholder in this study is the wedding organizer owner and the admin. The admin can be the staff of the wedding organizer that understands how to manage the user role. The owner of the wedding organizer can add an indicator for the calculation process and input the tradeshow event. Only the wedding organizer owner can calculate the alternative to prevent any unauthorized access to the result of the calculation process. Table 4 shows the user access right of the system.

Table 4 - User Access Rights

\begin{tabular}{cc}
\hline Role & Access Rights \\
\hline Admin & Manage user account \\
WO Owner & Input indicator, Input tradeshow event, Calculate alternative \\
\hline
\end{tabular}

To design the decision support system, it is needed to develop the decision model first. The model development phase consist of three phase which are criteria identification, weight calculation, and model development [1] [24] [25]. After the model is developed the next step is to validate the model. Validation test is conduct to ensure that the model is representing the real system. The criteria that is used in this study is based on the literature review and interview with the wedding organizer owner that have an experience in participating in the tradeshow / expo. The weighting process for the model is done using the Analytical Hierarchy Process method. The weight of each criteria is obtained from the interview with 5 wedding organizer owner that have experience in the tradeshow / expo. Table 5 shows the criteria result. From the table it is known that event attractiveness is the most highest weight, and the lowest weight is the cost estimation. According to the association, this can happen because most of the wedding organizer never considered money as constrain, the wedding organizer is willing to participate in the tradeshow even the cost of participating is quite high as long as there are potential client in the tradeshow event. 
Table 5 - Weight of Criteria Result

\begin{tabular}{ccc}
\hline Code & Criteria & Weight \\
\hline$C 1$ & Tradeshow location & $3.1 \%$ \\
$C 2$ & Exhibitor reputation & $3.3 \%$ \\
$C 3$ & Cost estimation & $2.8 \%$ \\
$C 4$ & Prestige of event & $15.6 \%$ \\
$C 5$ & Other tenant reputation & $20.7 \%$ \\
$C 6$ & Event time & $6.7 \%$ \\
$C 7$ & Event attractiveness & $40.8 \%$ \\
\hline
\end{tabular}

To ensure the consistency of the assessment from respondent, consistency check is conducted. If the consistency ratio of the calculation is below 0.1 (consistency ratio $\leq 0.1$ ) then the assessment is consistent [13]. Table 6 shows the consistency result. From the table it is known that the consistency ratio value is 0.073 and the result is below 0.1 , therefore the calculation process of AHP is consistent. The weight for each criteria will be used as an input in the alternative calculation process.

Table 6 - Consistency Ratio Result

\begin{tabular}{cc}
\hline Consistency & Value \\
\hline$\lambda \max$ & 7.588 \\
Consistency Index & 0.098 \\
Consistency Ratio & 0.073 \\
\hline
\end{tabular}

After the model is developed, the next step is to create the system models. Figure 2 shows the design of the database for the decision support system.

\begin{tabular}{|c|c|c|c|c|c|}
\hline \multicolumn{2}{|r|}{ indikator } & \multicolumn{2}{|r|}{ tradeshow_calc } & \multicolumn{2}{|r|}{ tradeshow } \\
\hline PK & id_ind & PK & id_tc & PK & id_ts \\
\hline & $\begin{array}{l}\text { indicator_name } \\
\text { indicator_weight } \\
\text { indicator_type }\end{array}$ & FK1 & $\begin{array}{l}\text { id_ts } \\
\text { id_ind } \\
\text { norm }\end{array}$ & & $\begin{array}{l}\text { ts_name } \\
\text { ts_date } \\
\text { ts_place }\end{array}$ \\
\hline & & & W_norm & & ts_loc \\
\hline
\end{tabular}

Fig. 2 - Database Design

Usecase diagram is used to describe how the system must behave to meet stakeholder expectation as an actor to the system. Figure 3 (a) shows the usecase for login, the actor that involved in this action is the wedding organizer owner and the admin, both user can login to the system and will be authenticate first, the system will check if the user is exist and if the username and password match with the one in the system. Figure 3 (b) shows the usecase diagram for calculate the tradeshow alternative using TOPSIS. The actor on this usecase is only the wedding organizer owner. First, the wedding organizer owner must input the criteria / indicator first, the criteria that is used for this system is obtained from the decision model in the previous section (Table 5). After the criteria is obtained, the next step is input the criteria value of each tradeshow event. The value is specifiy by the owner according to each of the criteria that is choose before. After the value is submitted, then the wedding organizer can see the calculation result, the system will display the tradeshow alternative ranking.

After the basic requirement is defined, the next phase is to design the system mockup, the design of the mockup is created based on the requirements and the product backlog. Figure 4 (a) shows the mockup for login page, user is asked to input the username and password to access the content of the system. The login button is placed right below the input text to ease the user. Figure 4 (b) shows the mockup page for add new tradeshow, to input new tradeshow to the system it requires the name of the tradeshow, place of the tradeshow, date of the event, and the geolocation of the tradeshow. 
a

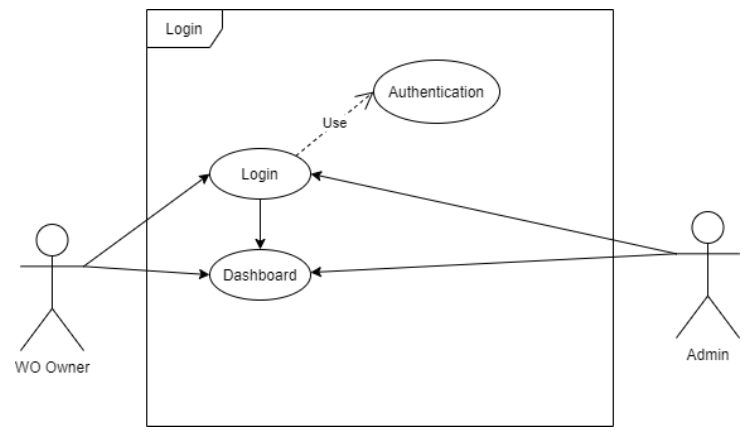

$\mathrm{b}$

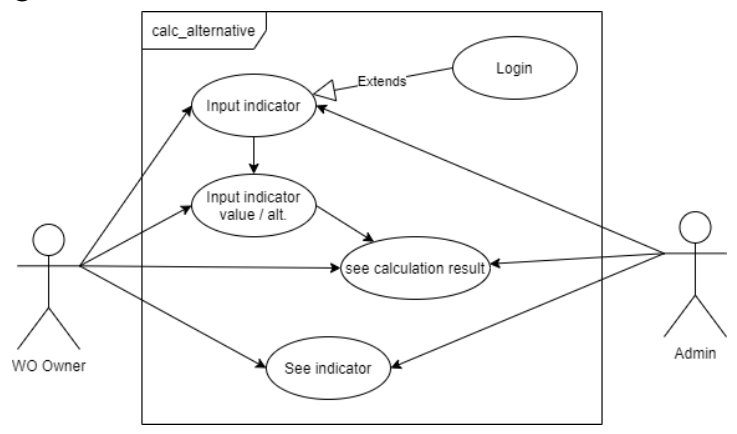

Fig 3 - Usecase login (a);Usecase calculate tradeshow selection (b)

Figure 5 (a) shows the mockup design for adding new indicator to the system. To add new indicator it requires the wedding organizer owner to input the indicator name, indicator weight (obtained from Table 5) and the indicator type. The type of the indicator (lower the better, more the better) is used as mark for the calculation result, it is used to specify whether the calculation of indicator must select the maximum value or the minimum value as the basis in the normalization matrix. Figure 5 (b) shows the mockup design to calculate the alternatives. User must input the values of each criteria/indicator for each tradeshow. The value may vary according to each units of the criteria. The calculation page is present as a table to ease the user when input the value. Figure 6 shows mockup design for the result of the calculation. The result contain the tradeshow alternatives, the value of $\mathrm{Si}+, \mathrm{Si}-$, and the $\mathrm{Pi}$. The ranking of each alternatives is also shown to give user information about the highest ranking from the calculation.

a

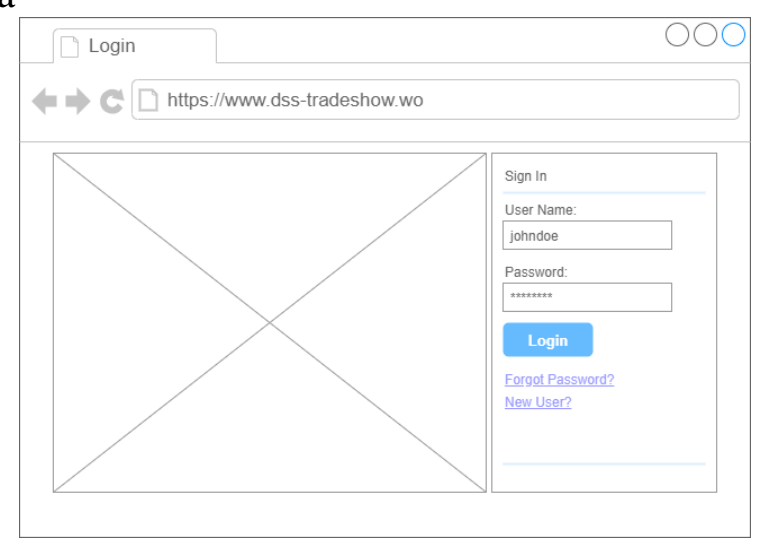

$\mathrm{b}$

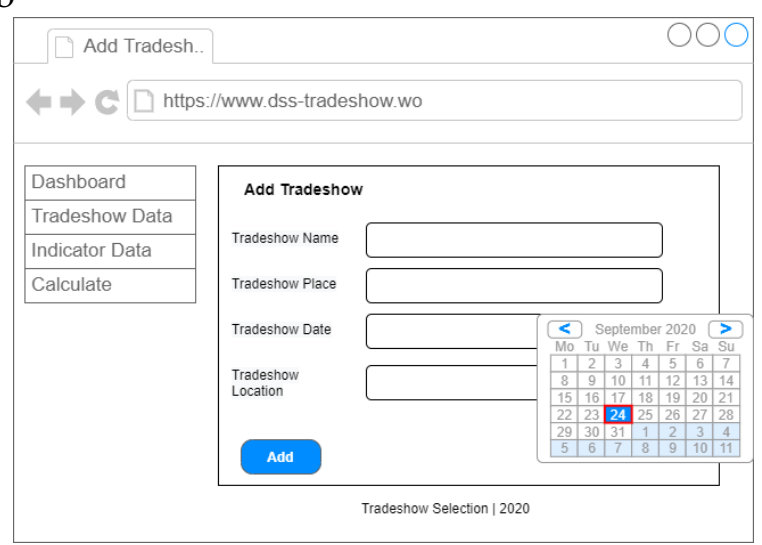

Fig 4 - Mockup for login (a);Mockup for add tradeshow(b)

$\mathrm{a}$

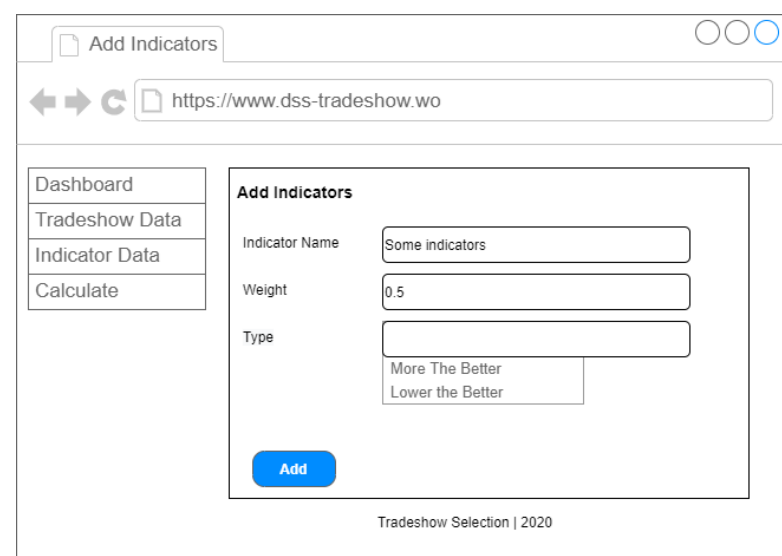

b

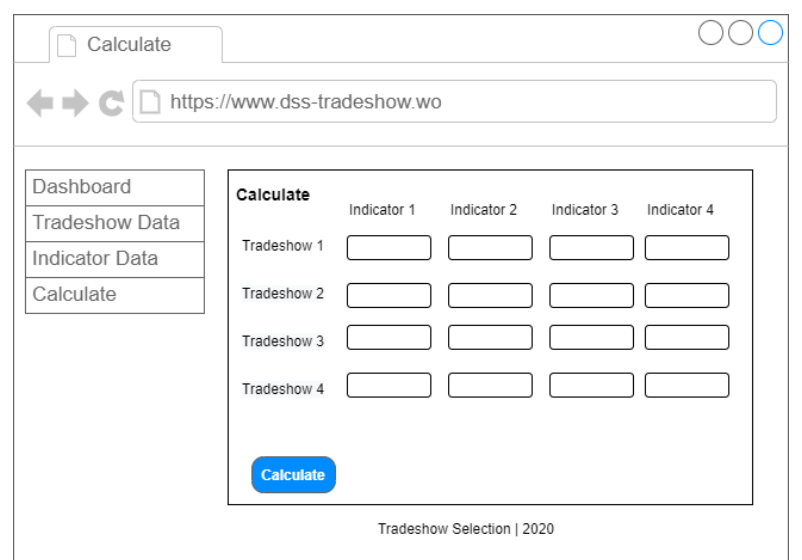

Fig 5 - Mockup for add indicators (a);Mockup for add calculate tradeshow selection (b) 


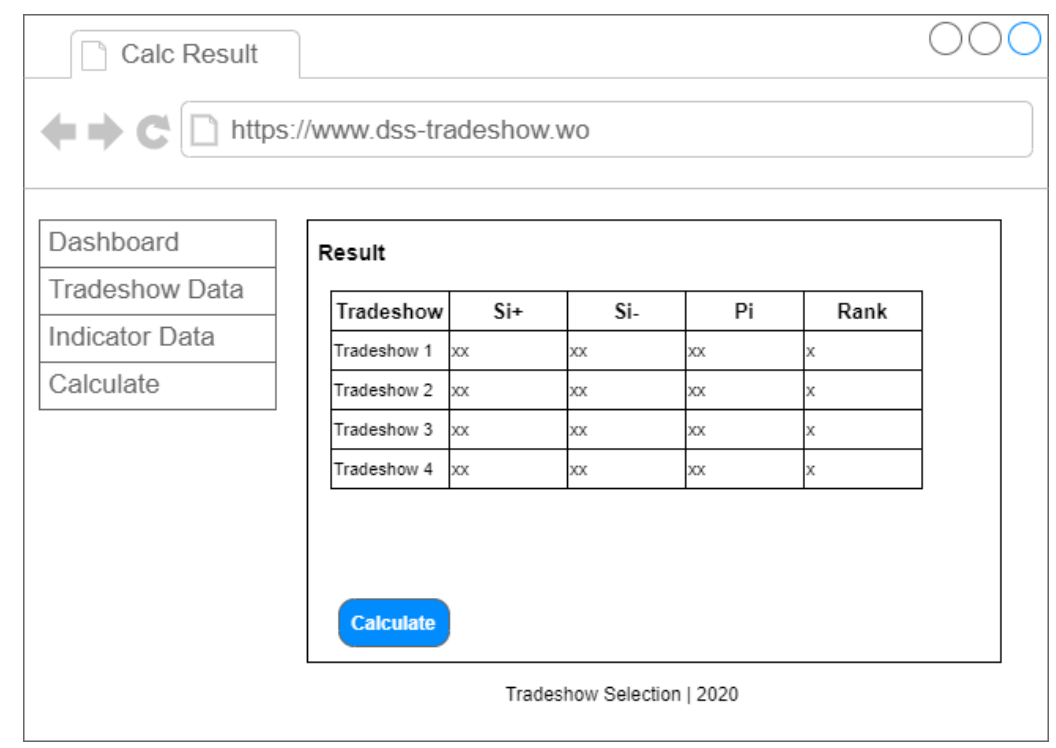

Fig. 6 - Calculation result mockup

After the mockup is designed, the next step is to transform the mockup design into code. Figure 7 (a) shows the add tradeshow page, to input new tradeshow to the system it requires the name of the tradeshow, place of the tradeshow, date of the event, and the geolocation of the tradeshow. All the page is based on the mockup design from previous step. Figure 7 (b) shows the page for input new indicator. To add new indicator, the wedding organizer owner must input the indicator name, indicator weight and the indicator type.

a

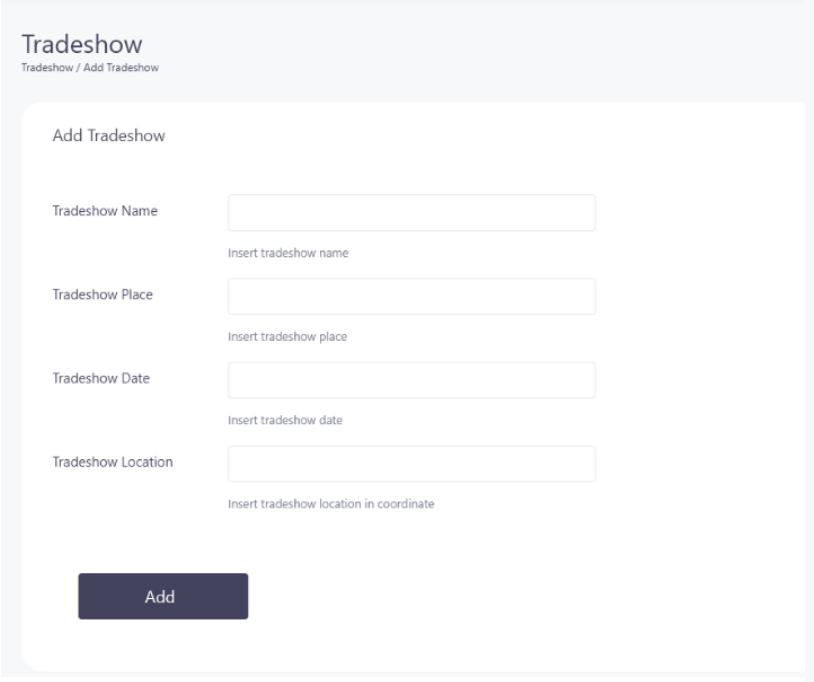

b

Indicator dicator/Add Indicator

Add Indicator

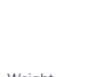

Add

Fig 7 -Add tradeshow page (a); Add indicator page (b)

Figure 8 shows the calculation page, in this page all indicators and all tradeshow is loaded and must be given value, all the input is set to required so there must be no blank value in the system. Figure 9 shows the calculation result page. The result of the calculation is the ranking of each alternatives. The decision support system that is designed in this study only display the suggestion about the tradeshow alternatives. The selection process is the wedding organizer rights by taking the calculation result into consideration.

After the interface is designed and coded, the next step is to test whether the system is functional. The functional testing is done by using the black box method. The black box testing is a method for testing the system which the tester knows the expected behavior from the system and make sure the output is the same as in the designed phase [26]. The purpose of this testing is to make sure that the designated feature is fully functional and meet the 
expectation. The testing scenario in this research consist of all feature that is included in the system. Table 7 shows the functional testing result.

Table 7 - Functional Testing Result

\begin{tabular}{ccc}
\hline Identification & Description & Status \\
\hline$T C-01$ & Login testing with various role & Succes \\
$T C-02$ & Tradeshow data page testing & Succes \\
$T C-03$ & Criteria data page testing & Succes \\
$T C-04$ & Calculation page testing & Success \\
$T C-05$ & User management menu testing in admin & Succes \\
\hline
\end{tabular}

According to the functional test, all function is meet the expected behaviour, all scenario is conducted without any problem. User Acceptance Test (UAT) is a questionnaire-based evaluation to verified the system functionality from the user perspective. The acceptance is based on 5 aspects which are design, responsiveness, reliability, and trust. The acceptance test is done with the wedding organizer owner. Table 8 shows the user acceptance test result, it is known that all function in the system tested and all the function is worked. Moreover, the user acceptance test also performed in this study. The result is $91.7 \%$ of the respondents satisfied with the system.

Table 8 - User Acceptance Test

\begin{tabular}{|c|c|c|c|c|}
\hline \multirow{2}{*}{$\begin{array}{c}\text { Dimension } \\
\text { Design }\end{array}$} & \multicolumn{2}{|c|}{ Yes } & \multicolumn{2}{|c|}{ No } \\
\hline & $4 / 4$ & $100 \%$ & $0 / 4$ & $0 \%$ \\
\hline Responsive & $2 / 2$ & $100 \%$ & $0 / 2$ & $0 \%$ \\
\hline Reliability & $2 / 3$ & $67 \%$ & $1 / 3$ & $33 \%$ \\
\hline Trust & $1 / 1$ & $100 \%$ & $0 / 1$ & $0 \%$ \\
\hline Total & $9 / 10$ & $91,7 \%$ & $1 / 10$ & $8,3 \%$ \\
\hline
\end{tabular}

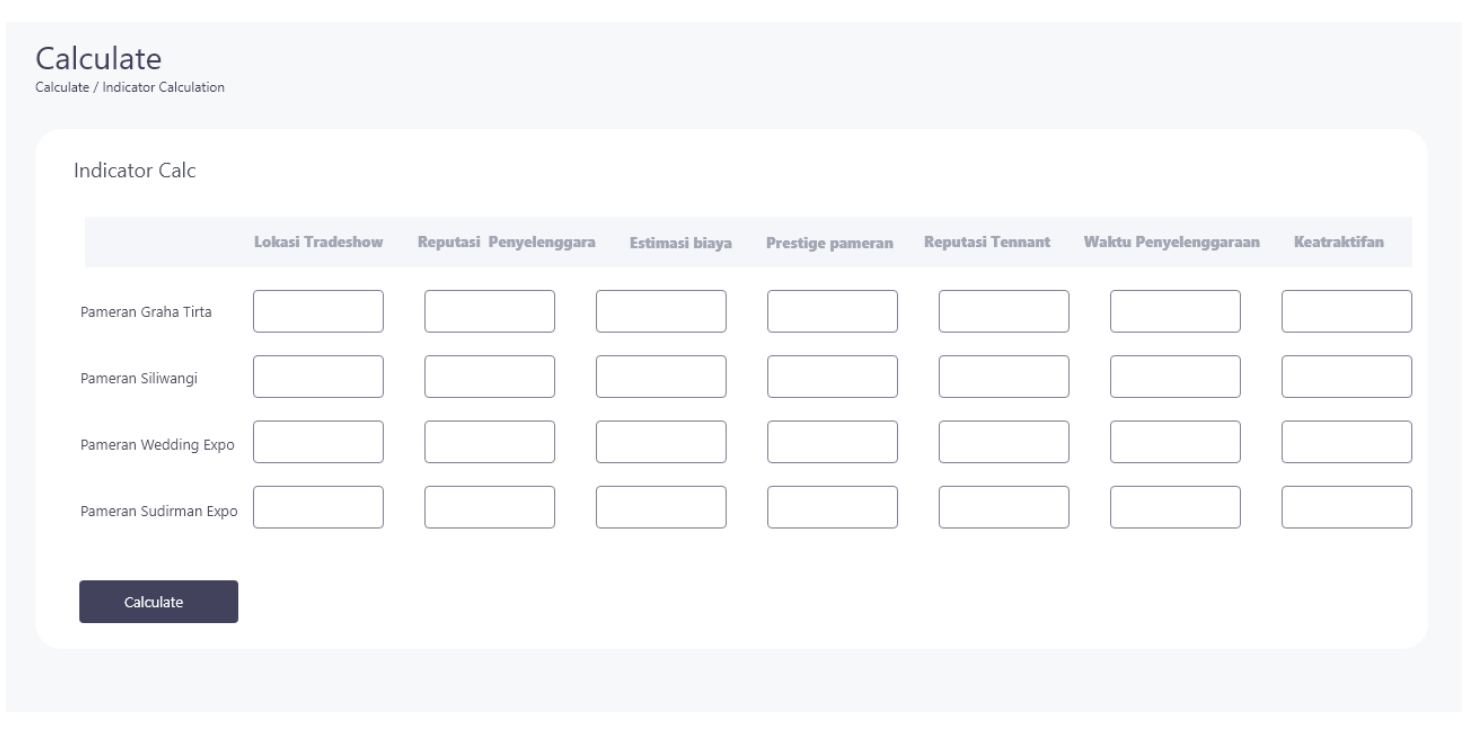

Fig 8 - Calculation page 


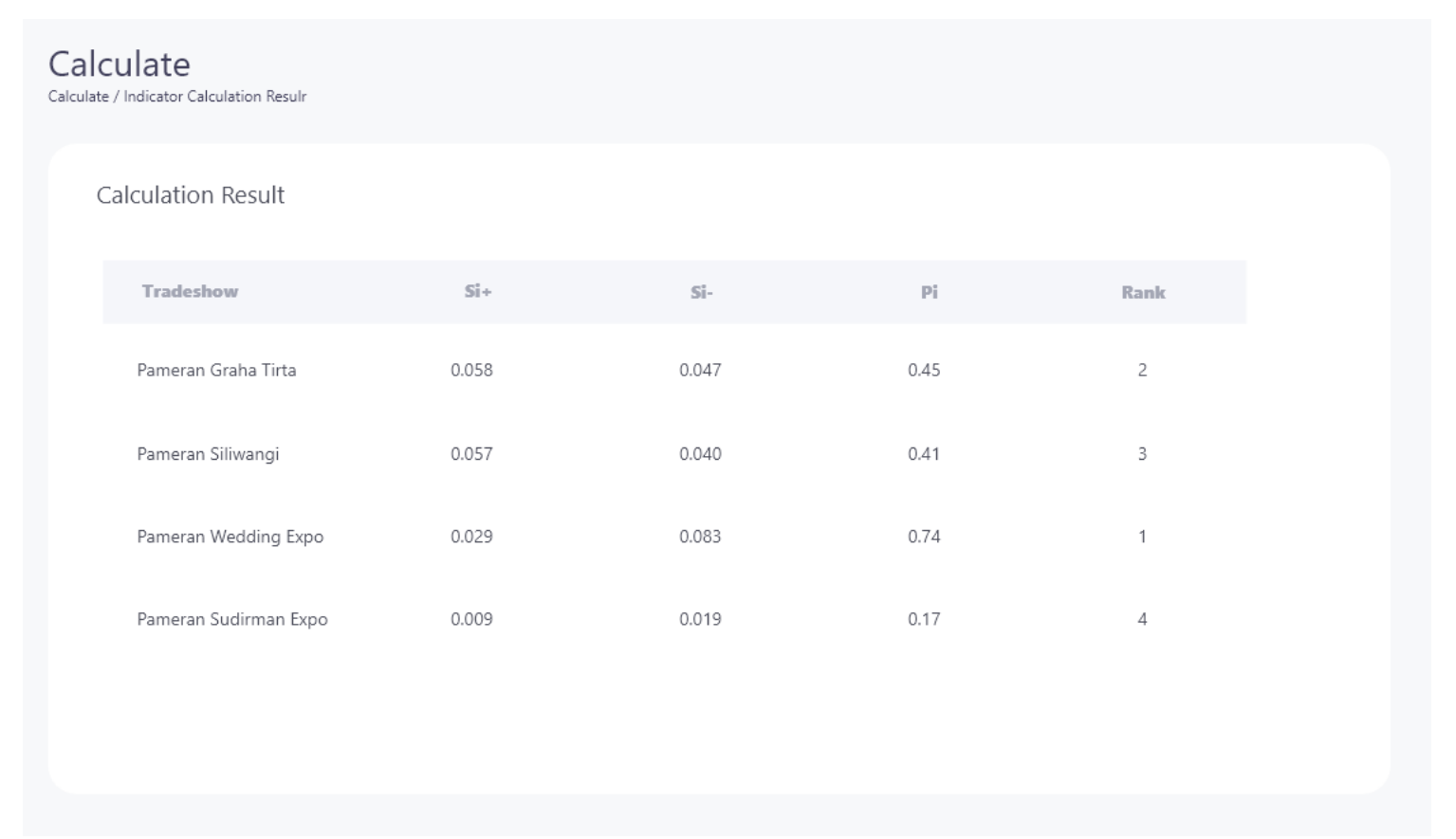

Fig 9 - Calculation result page

\subsection{Discussion}

In the requirement identification phase, the stakeholder is identified. The stakeholder is needed to gain better perspective about what is the needs of the designated decision support system. The previous study from Rizana et al. [1] is combined with the insight from the stakeholder to gain more suitable criteria to choose the trade show. the result of this study shows the acceptance level of $91.7 \%$, this means that the stakeholder in this case is the owner feel that the designated DSS is comply to their needs, but there is a room of improvement for this research, in example in reliability the average score is $67 \%$ this means that the DSS can be improved to be more reliable. One of action that can be done is to make sure that the hardware infrastructure of the DSS is comply to the minimum specification. For the wedding organizer owner, the result of this study can be used as a basis for determining which trade show event hat must be entered, if the owner have an event calendar of the trade show for the following year, the DSS can give alternatives which of the events must be enter with the desirable budget and impact. For the trade show organizer, this study can be used as a standard to hosting an wedding trade show. There is a limitation in the study, such as there are others criteria that is not considered in this study such as the quality of service offered by organizers. According to Lin [27], Satisfaction with the organizers is probably an indispensable factor in determining the positive behavioral intention of the exhibitors. The quality of serviced is intangible and is perceived by the exhibitors, this can be included in further study.

\section{Conclusion}

The purpose of this study is to design a decision support system to determine the participation of a wedding organizer in a trade show. There are seven factors used in this study to develop the decision model i.e. tradeshow location, reputation and professionalism of the organizer, cost estimation, trade show prestige, tenant reputation, time of the event, attractiveness of the event. The decision model was constructed using AHP and TOPSIS. The decision model constructed in this study, then used as a rule in design the decision support system. The system design in this study has several features such as input the trade show event data, input and edit the factor and the weight of the factor, calculate the score of the trade show, and the recommendation of the participation. Moreover, the system also have the dashboard page that can show the statistic of the tradeshow score, the recommendation, etc. All the function in the system then tested and all the function is worked. Moreover, the user acceptance test also performed in this study. The result is $91.7 \%$ of the respondents satisfied with the system.

\section{Disclaimer}

The authors whose names are written certify that they have no conflict of interest. 


\section{References}

[1] A. F. Rizana, R. P. Soesanto, and A. Kurniawati, "Model Penilaian dan Pemilihan Trade Show Bagi Industri Kreatif di Sektor Mode,” J. Ilm. Tek. Ind., vol. 16, no. 1, p. 73, 2017, doi: 10.23917/jiti.v16i1.3872.

[2] W. Tafesse and K. Skallerud, “A systematic review of the trade show marketing literature: 1980-2014,” Ind. Mark. Manag., vol. 63, pp. 18-30, 2017, doi: 10.1016/j.indmarman.2016.11.001.

[3] B. P. Brown, M. Mohan, and D. Eric Boyd, "Top management attention to trade shows and firm performance: A relationship marketing perspective," J. Bus. Res., vol. 81, pp. 40-50, 2017, doi: 10.1016/j.jbusres.2017.07.020.

[4] C. H. Lee and S. Y. Kim, "Differential effects of determinants on multi-dimensions of trade show performance: By three stages of pre-show, at-show, and post-show activities," Ind. Mark. Manag., vol. 37 , no. 7, pp. 784-796, 2008, doi: 10.1016/j.indmarman.2008.01.006.

[5] Y. Lin, J. Jiang, and D. Kerstetter, "A Three-Component Framework for Trade Show Performance Evaluation,” J. Hosp. Tour. Res., vol. 42, no. 6, pp. 855-879, 2015, doi: 10.1177/1096348015619747.

[6] J. K. Nayak, "An exhibitors perspective: factors affecting selection of industrial trade shows in India and the importance of spot sales," J. Business-to-bus. Mark., vol. 26, no. 2, pp. 125-140, 2019, doi: 10.1080/1051712X.2019.1603356.

[7] F. Mohd, W. F. F. A. Wan Yahya, S. Ismail, M. A. Jalil, and N. M. M. Noor, “An Architecture of Decision Support System for Visual-Auditory-Kinesthetic (VAK) Learning Styles Detection Through Behavioral Modelling," Int. J. Innov. Enterp. Syst., vol. 3, no. 02, pp. 24-30, 2019, doi: 10.25124/ijies.v3i02.37.

[8] H. Paul, O. Bradley, and P. F. A., “Trade show: who, what, why,” Mark. Intell. Plan., vol. 16, no. 7, pp. 425435, Jan. 1998, doi: 10.1108/02634509810244444.

[9] Y. Lin, “An examination of determinants of trade show exhibitors' behavioral intention: A stakeholder perspective,” Int. J. Contemp. Hosp. Manag., vol. 28, no. 12, pp. 2630-2653, 2016, doi: 10.1108/IJCHM-062015-0318.

[10] L. Guan, Y. Luo, and L. R. Tang, "An exploratory study of decision makers for choosing wedding banquet venues: push and pull motivations," Int. J. Tour. Cities, vol. 1, no. 2, pp. 162-174, 2015, doi: 10.1108/IJTC08-2014-0011.

[11] C. K. H. Lau and S. H. Hui, "Selection attributes of wedding banquet venues: An exploratory study of Hong Kong prospective wedding couples," Int. J. Hosp. Manag., vol. 29, no. 2, pp. 268-276, 2010, doi: 10.1016/j.ijhm.2009.10.008.

[12] E. G. Ardani, “The Importance of the Venue Selection in an Event Organization Case Study: Special Event Organization Rencontre Alumni Entreprise 1 \& 2," E-Journal Tour., vol. 4, no. 1, pp. 46-54, 2017, doi: 10.24922/eot.v4i1.30168.

[13] T. L. Saaty, "Decision making with the Analytic Hierarchy Process," Int. J. Serv. Sci., vol. 1, no. 1, pp. 8398, 2008, doi: 10.1504/ijssci.2008.017590.

[14] M. Bevilacqua and M. Braglia, "The analytic hierarchy process applied to maintenance strategy selection," Reliab. Eng. Syst. Saf., vol. 70, no. 1, pp. 71-83, 2000, doi: https://doi.org/10.1016/S0951-8320(00)00047-8.

[15] A. Dirpan, "Combining an Analytic Hierarchy Process and TOPSIS for Selecting Postharvest Technology Method for Selayar Citrus in Indonesia," IOP Conf. Ser. Earth Environ. Sci., vol. 156, no. 1, 2018, doi: 10.1088/1755-1315/156/1/012031.

[16] F. M. Kasie, G. Bright, and A. Walker, "Decision support systems in manufacturing: a survey and future trends," J. Model. Manag., vol. 12, no. 3, pp. 432-454, 2017, doi: 10.1108/JM2-02-2016-0015.

[17] J. Singh, P. Shukla, and S. P. Kalafatis, "IT usage for enhancing trade show performance: evidence from the aviation services,” J. Bus. Ind. Mark., vol. 32, no. 3, pp. 398-408, 2017, doi: 10.1108/JBIM-11-2014-0245.

[18] M. C. Layton, "Scrum for Dummies - A Wiley Brand,” p. 403, 2015.

[19] K. Schwaber and J. Sutherland, “Scrum Guide," vol. 19, no. 6, p. 504, 2017, doi: 10.1053/j.jrn.2009.08.012.

[20] Philosophie, Agile Handbook. Philosophie, 2019.

[21] H. A. Fatimah and R. Trisminingsih, "Analyzing Success Factors of Enterprise Resource Planning Adoption using Analytical Hierarchy Process," Int. J. Innov. Enterp. Syst., vol. 2, no. 01, pp. 45-49, 2018, doi: 10.25124/ijies.v2i01.16. 
[22] J. Dick, E. Hull, and K. Jackson, Requirements engineering. 2017.

[23] H. G. Daellenbach and D. C. McNickle, Management science: decision making through systems thinking. New York: Palgrave Macmillan, 2005.

[24] S. Destari and B. K. Simpony, "Sistem Pendukung Keputusan Pemilihan Wedding Organizer Menggunakan Metode AHP," J. Tek. Komput. AMIK BSI, vol. 3, no. 2, pp. 416-420, 2018.

[25] A. F. Rizana and R. P. Soesanto, "Design of Decision Support System Application for Determining Scholarship Grantee Using Analytical Hierarchy Process and Factor Rating," Mar. 2019, doi: 10.2991/icoiese-18.2019.1.

[26] M. Larrea, "Black-Box Testing Technique for Information Visualization. Sequencing Constraints with LowLevel Interactions,” J. Comput. Sci. Technol., vol. 17, no. 1, pp. 37-48, 2017.

[27] Y. Lin and Y. Tu, "Computers \& Education The values of college students in business simulation game : A means-end chain approach,” vol. 58, pp. 1160-1170, 2012, doi: 10.1016/j.compedu.2011.12.005. 